\title{
ACÚMULO DE MATÉRIA SECA E ÓLEO EM SEMENTES DE PINHÃO-MANSO IRRIGADO E DE SEQUEIRO
}

Doi:http://dx.doi.org/10.1590/1809-4430-Eng.Agric.v35n5p829-837/2015

\section{ADÃO W. P. EVANGELISTA ${ }^{1}$, JOSÉ ALVES JÚNIOR ${ }^{2}$, JORGE L. M. SOUZA ${ }^{3}$, RICARDO DE S. BEZERRA ${ }^{4}$, MARCUS V. H. DOMINGOS ${ }^{5}$}

\begin{abstract}
RESUMO: Avaliou-se o efeito da irrigação e de fases de maturação dos frutos sobre o rendimento em massa de matéria seca e de óleo de sementes de pinhão-manso. $\mathrm{O}$ experimento foi conduzido na área experimental do departamento de Agricultura da Universidade Federal de Lavras - UFLA, em Lavras-MG, em uma lavoura de pinhão-manso irrigada por gotejamento, com três anos de idade. Frutos de pinhão-manso foram classificados em quatro fases de maturação, assim denominadas: F1 (frutos totalmente verdes e sementes brancas); F2 (20\% de frutos verdes e o restante amarelos, marrons e secos); F3 (frutos amarelos com partes marrons, com início de deiscência e sementes pretas); e F4 (frutos marrons escuros, secos e deiscentes). As sementes foram extraídas para a determinação do teor de água, dimensões principais, volume, massa seca de mil sementes e teor de óleo. O delineamento experimental utilizado foi o inteiramente casualizado, em esquema fatorial 4 X 2 (4 fases de maturação dos frutos e duas formas de manejo de água - irrigado e sequeiro) e 3 repetições. A colheita de frutos na coloração marrom, em plantas irrigadas, proporcionou maior rendimento em massa seca e rendimento de óleo de sementes de pinhão-manso.
\end{abstract}

PALAVRAS-CHAVE: Jatropha curcas L., maturação fisiológica, manejo de água.

\section{OIL AND DRY MATTER ACCUMULATIONS IN SEEDS OF IRRIGATED AND NON- IRRIGATED JATROPHA}

\begin{abstract}
In this study, we evaluated the effects of irrigation and maturity stage on dry matter and oil accumulations of Jatropha curcas seeds. The trial was performed in an experimental area of the Department of Agriculture in the Federal University of Lavras - UFLA in Minas Gerais state, Brazil. The area was grown with 3-year-old drip-irrigated plantation of jatropha. Fruit were collected and classified into four maturity stages as follows: green fruit with white seeds (F1), $20 \%$ green fruit and $80 \%$ yellow and/or brown dry fruit (F2), yellow fruit with brown parts in early dehiscence and black seeds (F3), brown dry and dehiscent fruit (F4). After being extracted, seed moisture, main dimensions, volume, dry matter and oil content were measured. The experimental design was randomized in a 4X2 factorial model (4 maturity stages - F1, F2, F3 and F4, and two water managements - irrigated and rainfed) with three replications. Brown fruit seeds provided higher yields of dry matter and oil content.
\end{abstract}

KEYWORDS: Jatropha curcas L., physiological maturity, water management.

\section{INTRODUÇÃO}

A crescente preocupação ambiental relacionada às mudanças climáticas globais e à busca por alternativas que reduzam as emissões de gases causadores do efeito estufa, intensificou as ações internacionais voltadas ao desenvolvimento de programas de substituição dos combustíveis fósseis

\footnotetext{
${ }^{1}$ Eng $^{\circ}$ Agrícola, Prof. Doutor, Setor de Engenharia de Biossistemas, UFG/Goiânia - GO, Fone: (62) 3521-1667, awpego@pq.cnpq.br

${ }^{2}$ Eng $^{\mathbf{o}}$ Agrônomo, Prof. Doutor, Setor de Engenharia de Biossistemas, UFG/Goiânia - GO, josealvesufg @ yahoo.com.br

${ }^{3}$ Eng $^{\circ}$ Agrícola, Prof. Doutor, Departamento de Solos e Engenharia Agrícola, UFPR/Curitiba - PR, jmoretti@ufpr.br

${ }^{4}$ Eng $^{\mathrm{o}}$ Agrônomo, Doutorando em Agronomia, Setor de Engenharia de Biossistemas, UFG/Goiânia - GO, rsbezerra.agro@gmail.com

${ }^{5}$ Graduando em Agronomia, Setor de Engenharia de Biossistemas, UFG/Goiânia - GO, marcus-domingos@hotmail.com 
por combustíveis produzidos a partir de fontes renováveis, como o biodiesel. De acordo com o Plano Nacional de Agroenergia, um dos desafios é maximizar o aproveitamento das potencialidades regionais e a obtenção do benefício social da produção do biodiesel, aplicando a tecnologia, tanto às culturas tradicionais, quanto às novas.

Dentre as culturas energéticas, o pinhão-manso tem-se destacado nas discussões sobre oleaginosas potenciais para o fornecimento de óleo para a produção de biodiesel (ANDRÉOSOUZA et al., 2010; PARAWIRA, 2010), sendo uma cultura rústica, adaptada às mais diversas condições edafoclimáticas. Entretanto, apresenta frutificação irregular e, consequentemente, maturação desuniforme, o que força os produtores a realizarem inúmeras etapas de colheita durante o ciclo produtivo (MARTINS et al., 2010). A desuniformidade no processo de maturação dos frutos tem sido um problema para sua produção em grande escala. Por um lado, a realização da colheita em uma única etapa pode refletir em excessiva quantidade de sementes imaturas, malformadas e chochas, com consequente diminuição do rendimento por área, e quando a colheita é realizada em várias etapas, pode resultar em maior gasto com mão de obra e redução dos lucros para o produtor (MAEDA et al., 1997).

O processo de maturação culmina quando a semente atinge a máxima massa de matéria seca (LAMARCA et al., 2013). Os índices baseados nas mudanças morfológicas, bioquímicas e fisiológicas, como tamanho, densidade aparente, umidade e massa de matéria seca, são parâmetros que permitem inferir sobre a fase de maturação das sementes, fornecendo uma estimativa da época adequada para sua colheita (EVANGELISTA et al. 2010; PIÑA-RODRIGUES \& AGUIAR, 1993). DRANSKI et al. (2010) observaram que frutos de pinhão-manso, com epicarpo de coloração amarela com manchas marrons, apresentaram máximo acúmulo de matéria seca, teor de água inferior a $38,5 \%$ e sementes no ponto de maturidade fisiológica.

O fornecimento de água, para a maioria das culturas, de forma eficiente, interfere diretamente no processo de produção agrícola e também no processo de maturação das sementes (SCHIAVO et al., 2010). São cada vez mais frequentes os problemas climáticos que atingem severamente as culturas não irrigadas, mesmo em regiões climaticamente aptas. Neste caso, a irrigação é uma técnica que pode incrementar a produtividade das culturas. Em área experimental de pinhão-manso conduzido sob irrigação por sulcos, em Janaúba - MG, as plantas, aos 18 meses de idade, haviam produzido $2.500 \mathrm{~kg}$ de sementes por hectare, com rendimento de $38 \%$ de óleo (DRUMMOND et al., 2010).

JUHÁSZ et al. (2010), trabalhando com 50 acessos de pinhão-manso no norte do Estado de Minas Gerais, obtiveram a variação no teor de óleo entre os acessos em torno de $12,89 \%$, sendo o maior valor encontrado de 37,27\%, e o menor, de 24,39\%, enquanto em Campina Grande -PB, NERY et al. (2013) extraíram, pelo método de Soxhlet, aproximadamente 32,03\% de óleo, de sementes coletadas em plantas irrigadas com água salina.

Dentro deste contexto, o objetivo deste trabalho foi avaliar o efeito da irrigação e do estádio de maturação dos frutos sobre o rendimento em massa de matéria seca e de óleo das sementes de pinhão-manso.

\section{MATERIAL E MÉTODOS}

O experimento foi conduzido na área experimental do Setor de Fruticultura do Departamento de Agricultura da Universidade Federal de Lavras (UFLA), em Lavras, sul do Estado de Minas Gerais, em uma lavoura de pinhão-manso com 3 anos de idade. Em parte da área, as plantas eram cultivadas em regime de sequeiro, e a restante, irrigada por gotejamento. Utilizou-se de um sistema de irrigação com linhas laterais compostas por tubos gotejadores, com $16 \mathrm{~mm}$ de diâmetro, com emissores autocompensantes do tipo In-line com vazão de $1,6 \mathrm{~L} \mathrm{~h}^{-1}$, distanciados de $0,5 \mathrm{~m}$, permitindo que a superfície molhada formasse uma faixa contínua ao longo da linha de plantio. $\mathrm{O}$ manejo de irrigação foi realizado monitorando a umidade do solo por meio de sensores do tipo watermark. Para a utilização do sensor foi realizada uma prévia calibração do equipamento com o método-padrão de estufa, obtendo-se a equação $\theta_{\text {wat }}=9,16-0,195 \theta_{\text {estufa. As lâminas de irrigação }}$ 
foram calculadas de forma a aplicar a quantidade de água necessária para elevar a umidade do solo correspondente à capacidade de campo $\left(0,387 \mathrm{~cm}^{3} \mathrm{~cm}^{-3}\right)$. A porcentagem de área molhada foi de $16 \%$.

O solo da área experimental é classificado em Argissolo Vermelho eutrófico e apresentava as seguintes características na camada de 0 a $0,20 \mathrm{~m}: \mathrm{pH}\left(\mathrm{em} \mathrm{H}_{2} \mathrm{O}\right)=6,5$; $\mathrm{Al}$ trocável $\left(\mathrm{cmolc} \mathrm{dm}^{-3}\right)=$ 0,0; Ca+Mg $\left(\right.$ cmolc dm $\left.{ }^{-3}\right)=4,90 ; \mathrm{P}-$ Mehlich $\left.\left(\mathrm{mg} \mathrm{dm}^{-3}\right)=13,6 ; \mathrm{K}^{-3} \mathrm{mg} \mathrm{dm}^{-3}\right)=101,0$; Matéria orgânica $=2,1 \mathrm{~g} \mathrm{dm}^{-3} ; \mathrm{V}(\%)=73,1$; Soma de bases $=2,27\left(\mathrm{cmolc} \mathrm{dm}^{-3}\right) ; \mathrm{CTC}=7,1\left(\mathrm{cmolc} \mathrm{dm}^{-3}\right)$; $\mathrm{Zn}=3,6\left(\mathrm{mg} \mathrm{dm}^{-3}\right) ; \mathrm{Fe}=18,3\left(\mathrm{mg} \mathrm{dm}^{-3}\right) ; \mathrm{Mn}=20,3\left(\mathrm{mg} \mathrm{dm}^{-3}\right) ; \mathrm{Cu}=24,6\left(\mathrm{mg} \mathrm{dm}^{-3}\right) ; \mathrm{B}=0,4(\mathrm{mg}$ $\left.\mathrm{dm}^{-3}\right)$; argila $=614,4 \mathrm{~g} \mathrm{~kg}^{-1}$; silte $=77,8 \mathrm{~g} \mathrm{~kg}^{-1}$, e areia $=307,8 \mathrm{~g} \mathrm{~kg}^{-1}$.

O clima da região, segundo Koppen, é do tipo Cwb, caracterizado por uma estação seca entre abril e setembro, e uma estação chuvosa de outubro a março. Durante a realização do experimento, na região, a temperatura média do ar foi de $20,3{ }^{\circ} \mathrm{C}$, e as médias mínimas e máximas foram de 15,5 ${ }^{\circ} \mathrm{C}$ e $28,2{ }^{\circ} \mathrm{C}$, respectivamente. O mês mais frio foi junho, quando a temperatura média do ar foi de $17{ }^{\circ} \mathrm{C}$, com mínima de $10,8{ }^{\circ} \mathrm{C}$, e a umidade relativa média do ar foi de $68 \%$, com menor valor de $52,7 \%$, ocorrido no mês de setembro. O total da precipitação pluvial foi de $1.213,9 \mathrm{~mm}$, apresentando total médio para o mês mais chuvoso de $345,5 \mathrm{~mm}$ e $0,0 \mathrm{~mm}$ para o mês mais seco. Nos meses que antecederam a colheita, as médias das temperaturas mínima e máxima do ar foram de $17,8{ }^{\circ} \mathrm{C}$ e $29,64{ }^{\circ} \mathrm{C}$, a umidade relativa média do ar foi de $66,5 \%$, e o total de precipitação, de 35 $\mathrm{mm}$.

Os frutos de pinhão-manso foram colhidos na área irrigada e de sequeiro, em diferentes fases de maturação, representados por colorações distintas, sendo elas: F1 (frutos totalmente verdes e sementes brancas); F2 (20\% de frutos verdes e o restante amarelos e marrons); F3 (frutos amarelos com partes marrons com início de deiscência e sementes pretas); F4 (frutos marrons escuros, secos e deiscentes) (Figura 1).

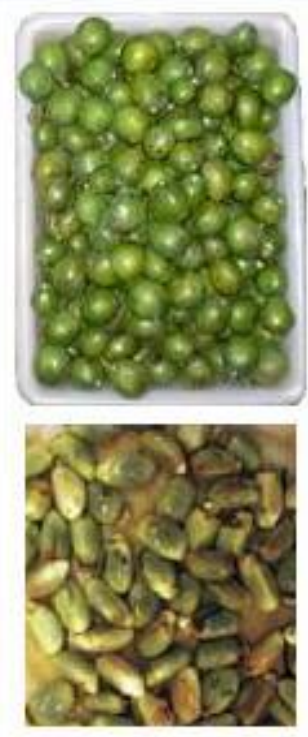

Fase 1
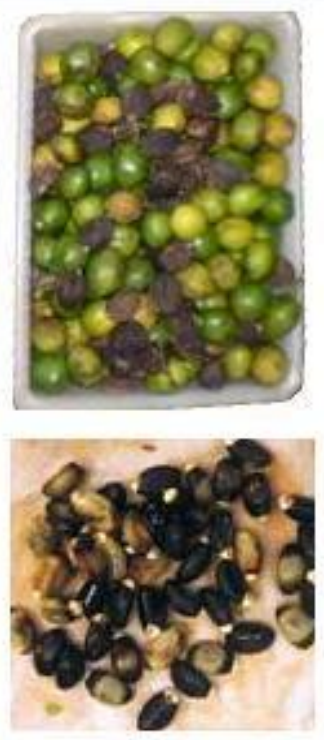

Fase 2
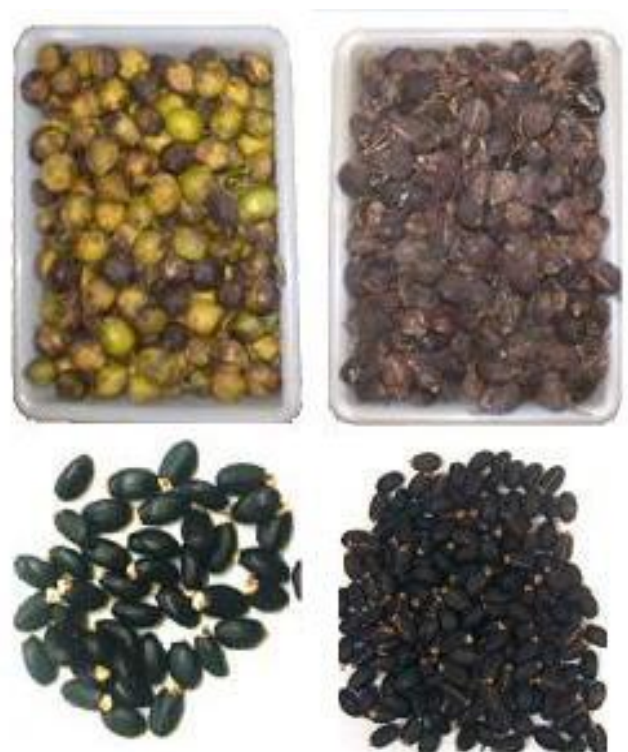

Fase 3

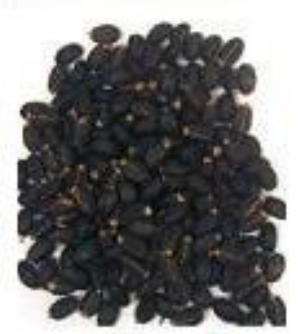

Fase 4

FIGURA 1. Frutos de pinhão-manso classificados de acordo com as fases de maturação. Classification of Jatropha curcas fruit according to the maturity stages.

Após serem classificados, retiraram-se amostras de frutos com massa de $3 \mathrm{~kg}$, colhidos nas áreas de sequeiro e irrigada. Em seguida, os frutos colhidos em cada fase de maturação foram descascados, e as sementes, extraídas, sendo determinados o teor de água (\% b.u.), as dimensões principais $(\mathrm{mm})$, o volume $\left(\mathrm{cm}^{3}\right)$, a massa de matéria seca de mil sementes $(\mathrm{g})$ e o percentual em massa de óleo. 
A umidade de sementes foi determinada pelo método da estufa, a $105{ }^{\circ} \mathrm{C}$, por 24 horas (BRASIL, 2009), com quatro repetições de $50 \mathrm{~g}$ de sementes colhidas em cada fase de maturação. Os resultados foram calculados com base na massa das sementes úmidas e foram expressos em porcentagem.

O comprimento, a largura e a espessura de 200 sementes de cada estádio de maturação foram determinados com auxílio de paquímetro digital $(0,01 \mathrm{~mm})$. Considerou-se como comprimento a região compreendida entre a porção basal e a apical da semente. A largura e a espessura foram tomadas na parte intermediária da semente. A massa de mil sementes colhidas em frutos, em cada estágio de maturação, foi determinada a partir da contagem de oito subamostras de 100 sementes tomadas ao acaso, sendo os valores expressos em gramas, conforme BRASIL (2009).

Para a determinação do teor de óleo de sementes, foi empregada a extração direta, utilizando hexano como solvente. As sementes foram descascadas, e as amêndoas foram trituradas. A extração foi feita em soxhlet por lixiviação do óleo contido nas sementes através de seu contato com o solvente, por um período de três horas, a uma temperatura de $70{ }^{\circ} \mathrm{C}$, conforme recomendação de MELHORANÇA FILHO et al. (2010). Em seguida, realizaram-se os cálculos de rendimento.

$\mathrm{O}$ delineamento experimental foi o inteiramente casualizado, em esquema fatorial 4 x 2, com três repetições. Os fatores de tratamento foram: quatro fases de maturação (F1; F2; F3 e F4) e formas de manejo da água (irrigado e sequeiro). Os resultados foram submetidos à análise de variância, e quando essa apresentou resultados significativos, as diferenças entre os tratamentos foram verificadas de acordo com teste de Tukey, ao nível de 5\% de probabilidade.

\section{RESULTADOS E DISCUSSÃO}

Houve interação significativa entre a irrigação e os estádios de maturação, para a umidade de sementes. Sementes de plantas irrigadas e de frutos colhidos no estádio verde foram as que apresentaram maior umidade (Tabela 1). Houve perda de umidade de sementes quando os frutos foram colhidos com a mudança de estádio verde para seco, e, ainda, a irrigação somente influenciou a umidade das sementes quando os frutos foram colhidos na coloração verde. Sementes extraídas de frutos verdes apresentaram, em média, umidade de 80,24\%, e, no decorrer do processo de maturação fisiológica, o percentual de umidade das sementes foi decaindo significativamente até alcançar o valor médio de $9,08 \%$. Verificou-se também que a umidade de sementes extraídas de frutos nos estádios maduros e secos não diferiu estatisticamente. E, finalmente, sementes de frutos colhidos no estágio seco e em plantas de sequeiro foram as que apresentaram a menor umidade.

TABELA 1. Valores médios de umidade (\%) em sementes de pinhão-manso colhidas em plantas irrigadas e de sequeiro, em diferentes estádios de maturação. Average moisture values $(\%)$ of jatropha seeds harvested in irrigated and non-irrigated plantations at different maturation stages.

\begin{tabular}{lccccc}
\hline \multirow{2}{*}{ Manejo de água } & \multicolumn{5}{c}{ Estádios de maturação } \\
\cline { 2 - 6 } & Frutos verdes & Frutos misturados & Frutos maduros & Frutos secos & Média \\
\hline Irrigado & $82,55 \mathrm{aA}$ & $33,41 \mathrm{aB}$ & $11,84 \mathrm{aC}$ & $9,46 \mathrm{aC}$ & 34,31 \\
Sequeiro & $77,94 \mathrm{bA}$ & $27,47 \mathrm{aB}$ & $11,02 \mathrm{aC}$ & $8,70 \mathrm{aC}$ & 31,28 \\
\hline Média & 80,24 & 30,44 & 11,43 & 9,08 & 32,79 \\
\hline
\end{tabular}

* Médias seguidas de mesma letra, maiúscula nas linhas e minúscula nas colunas, não diferem estatisticamente, pelo teste de Tukey, a $5 \%$ de probabilidade.

De acordo com CORVELLO et al. (1999), a manutenção do alto teor de água nas sementes, no início do processo de maturação, é necessária para que os produtos fotossintetizados nas folhas das plantas-mães sejam depositados na semente em desenvolvimento, sendo utilizados como fonte de formação e, posteriormente, como reserva. Este alto grau de umidade mantém-se presente até a semente alcançar o máximo de matéria seca, iniciando-se, a partir daí, um período com elevadas taxas de desidratação. No caso do pinhão-manso, durante todo o processo de maturação, as 
sementes permanecem protegidas por frutos carnosos, o que justifica a baixa redução do teor de água nas sementes colhidas do estágio maduro para o seco. Sementes contidas em frutos carnosos não passam, em geral, pela fase de rápida desidratação nem sofrem grandes oscilações em seu teor de água, em função da umidade relativa do ar.

As características morfológicas das sementes de pinhão-manso sofreram alterações significativas nos tratamentos. A irrigação e os estádios de maturação das sementes influenciaram separadamente nas dimensões principais das sementes de pinhão-manso (Tabela 2); entretanto, o manejo de água não influenciou no comprimento das sementes.

TABELA 2. Valores médios de dimensões principais de sementes de pinhão-manso colhidas em plantas irrigadas e de sequeiro e em diferentes estádios de maturação. Average values of main dimensions of jatropha seeds harvested in irrigated and non-irrigated plantations at different maturation stages.

\begin{tabular}{lccccccc}
\hline \multirow{2}{*}{ Parâmetros avaliados } & \multicolumn{4}{c}{ Estádios de maturação } & & \multicolumn{3}{c}{ Manejo de água } \\
\cline { 2 - 4 } \cline { 7 - 8 } & Verdes & Misturados & Maduros & Secos & & Irrigado & Sequeiro \\
\hline Comprimento $(\mathrm{mm})$ & $15,58 \mathrm{c}$ & $16,57 \mathrm{a}$ & $16,26 \mathrm{~b}$ & $16,87 \mathrm{a}$ & & - & - \\
Largura $(\mathrm{mm})$ & $10,14 \mathrm{~b}$ & $10,46 \mathrm{a}$ & $10,09 \mathrm{~b}$ & $10,50 \mathrm{a}$ & & $10,36 \mathrm{~A}$ & $10,24 \mathrm{~B}$ \\
Espessura $(\mathrm{mm})$ & $7,71 \mathrm{c}$ & $8,21 \mathrm{a}$ & $7,92 \mathrm{~b}$ & $8,23 \mathrm{a}$ & & $8,09 \mathrm{~A}$ & $7,94 \mathrm{~B}$ \\
Volume $\left(\mathrm{cm}^{3}\right)$ & $0,64 \mathrm{c}$ & $0,74 \mathrm{a}$ & $0,68 \mathrm{~b}$ & $0,76 \mathrm{a}$ & & $0,72 \mathrm{~A}$ & $0,69 \mathrm{~B}$ \\
\hline
\end{tabular}

* Médias na mesma linha seguidas pela mesma letra não diferem estatisticamente pelo teste de Tukey, a 5\% de probabilidade.

Sementes de frutos colhidos no estádio seco ou na proporção de $20 \%$ de frutos verdes e o restante amarelos, marrom e secos foram as que apresentaram os maiores valores médios de comprimento, largura, espessura e volume, enquanto os frutos colhidos no estádio verde foram os que apresentaram o pior resultado. Como houve diferença significativa entre o teor de água das sementes colhidas nos diferentes estádios, é provável que tenha prevalecido, nesses estádios, o efeito de contração volumétrica sobre o desenvolvimento das sementes, causado pela perda de água. Observou-se que, quando os frutos passaram do estádio de coloração verde para seco, ocorreu o acúmulo de reservas com consequente aumento das dimensões principais das sementes, e a perda de água resultou em contração volumétrica e, em contrapartida, redução das dimensões das sementes.

Quando a colheita foi realizada na proporção de $20 \%$ de frutos verdes e o restante amarelos e marrons, os resultados não foram influenciados, o que permite inferir que os frutos de pinhão-manso podem ser colhidos em uma única vez, quando estiverem nessa proporção nas plantas. Sementes de frutos colhidos em plantas irrigadas também foram as que apresentaram as maiores dimensões.

Os valores médios de massa seca de mil sementes para as sementes colhidas em plantas manejadas nos dois sistemas e nos estádios maduros, e na proporção de $20 \%$ de frutos verdes, e o restante amarelos e marrons, não diferiram entre si, porém foram significativamente maiores quando comparados com os das médias obtidas para sementes colhidas no estádio verde e menores que as colhidas no estádio seco, que apresentaram a maior média, sendo que a irrigação não influenciou sobre esse parâmetro avaliado (Tabela 3). Verifica-se, portanto, que a cor dos frutos é um parâmetro que pode ser utilizado como indicativo de maturidade de massa das sementes de pinhão-manso, fato também observado por PESSOA et al. (2012), ao relatarem que, do ponto de vista morfológico, a maturidade das sementes de pinhão-manso é facilmente acompanhada por mudanças visíveis no aspecto externo e na coloração dos frutos e das sementes. 
TABELA 3. Valores médios de massa de matéria seca de mil sementes de pinhão-manso colhidas em plantas irrigadas e em sequeiro, em diferentes estádios de maturação. Average values of one-thousand seed dry matter of jatropha seeds harvested in irrigated and non-irrigated plantations at different maturation stages.

\begin{tabular}{lcccc}
\hline \multirow{2}{*}{ Manejo de água } & \multicolumn{4}{c}{ Estádios de maturação } \\
\cline { 2 - 5 } & Frutos verdes $(\mathrm{g})$ & Frutos misturados $(\mathrm{g})$ & Frutos maduros $(\mathrm{g})$ & Frutos secos $(\mathrm{g})$ \\
\hline Irrigado & $343,18 \mathrm{aC}$ & $460,86 \mathrm{aB}$ & $478,16 \mathrm{aB}$ & $555,59 \mathrm{aA}$ \\
Sequeiro & $310,19 \mathrm{bC}$ & $440,99 \mathrm{bB}$ & $442,87 \mathrm{bB}$ & $542,68 \mathrm{aA}$ \\
\hline
\end{tabular}

* Médias seguidas de mesma letra maiúscula, nas linhas, e minúscula, nas colunas, não diferem estatisticamente, pelo teste de Tukey, a $5 \%$ de probabilidade.

O teor de óleo das sementes extraídas de frutos verdes foi 1,59 vez inferior ao das sementes extraídas de frutos secos, que estatisticamente, foi considerado igual ao teor de óleo extraído de sementes extraídas de frutos colhidos nos estádios maduro e na proporção de $20 \%$ de frutos verdes e o restante amarelos, marrons e secos, indicando que, a partir da coloração do fruto marrom-amarelo, o teor de óleo nas sementes pode ser considerado máximo. SANTOS et al. (2012) verificaram que sementes de pinhão-manso continham teor de óleo máximo quando os frutos passaram a apresentar sinais de maturação pela coloração amarela, mas observaram que tanto o acúmulo como a composição do óleo dependem também de fatores genéticos e condições de campo durante a maturação. GANGAL et al. (2009) observaram que durante a maturação de sementes de Putranjiva roxburghii ocorre um incremento no teor de óleo, tendendo a permanecer constante a partir de 23 dias após a antese, período que coincidiu com o período de máximo acúmulo de matéria seca nas sementes.

TABELA 4. Teor de óleo em sementes de pinhão-manso colhidas em plantas irrigadas e em sequeiro, em diferentes estádios de maturação. Oil content in seeds of jatropha seeds harvested in irrigated and non-irrigated plantations at different maturation stages.

\begin{tabular}{|c|c|c|c|c|c|c|}
\hline \multirow{2}{*}{ Parâmetros avaliados } & \multicolumn{4}{|c|}{ Estádios de maturação } & \multicolumn{2}{|c|}{ Manejo de água } \\
\hline & Verdes & Misturados & Maduros & Secos & Irrigado & Sequeiro \\
\hline Teor de óleo (\%) & $21,35 \mathrm{~b}$ & $33,21 \mathrm{a}$ & $34,35 \mathrm{a}$ & $32,91 \mathrm{a}$ & $31,67 \mathrm{~A}$ & $26,24 \mathrm{~B}$ \\
\hline
\end{tabular}

* Médias na mesma linha seguidas pela mesma letra não diferem estatisticamente, pelo teste de Tukey, a 5\% de probabilidade.

Em relação ao manejo de água, houve diferenças entre os dois tratamentos quanto ao teor de óleo das sementes (Tabela 4). O tratamento irrigado foi superior ao não irrigado, com rendimento de $31,67 \%$ contra $26,24 \%$ das plantas de sequeiro. Considerando uma produtividade média de sementes de $2.500 \mathrm{~kg} \mathrm{ha}^{-1}$, a produção de óleo obtida com as plantas irrigadas seria de 791,75 $\mathrm{kg} \mathrm{ha}^{-}$ ${ }^{1}$ e com as de sequeiro de $656 \mathrm{~kg} \mathrm{ha}^{-1}$, com a diferença, de $135,75 \mathrm{~kg} \mathrm{ha}^{-1}$ de óleo a favor da área irrigada.

Com bases nesses dados, justifica-se a irrigação de pinhão-manso na região de Lavras, mesmo essa região apresentando precipitação média anual de $1.500 \mathrm{~mm}$ (DANTAS et al., 2007), com ocorrência de veranicos. A reduzida disponibilidade de água é um dos fatores ambientais mais importantes na regulação do crescimento, desenvolvimento e produtividade de sementes e de óleo de plantas oleaginosas, e no caso do pinhão-manso, a cultura responde bem à irrigação, interferindo diretamente na produção, possibilitando de três a quatro colheitas por ano (DALLACORT et al., 2010).

Plantas oleaginosas cultivadas sem déficit hídrico normalmente produzem sementes com maior biomassa, permitindo afirmar que também produzem maior quantidade de óleo (MARCOS FILHO, 2005), justificando, assim, a redução do teor de óleo das sementes colhidas em plantas de sequeiro, pois durante o desenvolvimento do experimento observou-se que, no estágio de desenvolvimento dos frutos, ocorreram períodos de veranicos. Considerando veranicos como períodos com uma sequência de, no mínimo, quatro dias consecutivos com ocorrência de 
precipitações pluviométricas abaixo de $3 \mathrm{~mm}$, valor este que se aproxima ao da evapotranspiração de referência média diária da região, durante a realização do experimento, foi observada a ocorrência de 10 veranicos, com destaque para o ocorrido entre os meses de setembro e outubro, com duração de 45 dias.

Ressalta-se que, durante o desenvolvimento deste trabalho, foram visualizados sintomas de déficit hídrico nas plantas que não receberam irrigação, como murcha e desfolha. Os mesmos sintomas de déficit hídrico foram observados nas plantas em épocas de veranico em pesquisas realizadas com pinhão-manso irrigado no sul de Minas Gerais (PONCIANO DE DEUS et al., 2012; OLIVEIRA et al., 2009). Por outro lado, o florescimento do pinhão-manso pode ser induzido duas ou três vezes ao ano, por meio do manejo da irrigação, induzindo déficit hídrico durante um período suficiente para provocar a queda de metade das folhas da planta, para em seguida restabelecer a irrigação gradualmente (ANDRÉO-SOUZA et al., 2010). Como o florescimento é um dos principais estágios fenológicos para a produção de óleo do pinhão-manso, uma vez que o número de flores femininas e sua fecundação determinam quantos frutos e sementes serão desenvolvidos, ressalta-se novamente a importância do uso da irrigação, visando ao sucesso com essa cultura.

SOUSA et al. (2011), ao avaliarem os efeitos da aplicação de lâminas de irrigação sobre a produtividade e o rendimento de óleo de sementes de pinhão-manso, verificaram que o teor de óleo foi significativamente influenciado pelos diferentes níveis de reposição hídrica $(\mathrm{RH})$ aplicados. Os autores observaram que houve o decréscimo de 11,51;23,02 e 34,52\% no teor de óleo das sementes de pinhão-manso, para os níveis de $75 \%, 50 \%$ e $25 \%$ de $\mathrm{RH}$, e acréscimo de $11,51 \%$ no nível de RH $125 \%$, em comparação ao de RH $100 \%$, que foi de $31,33 \%$. No estudo de reposição hídrica em mamona, foi encontrado efeito significativo para teor de óleo (NUNES et al., 2013), sendo que as plantas irrigadas com maiores lâminas de reposição produziram maior biomassa, permitindo inferir que também produzem maior quantidade de óleo. Na região sul do Estado de Minas Gerais, a irrigação produziu efeitos significativos sobre o crescimento e a produtividade de sementes de pinhão-manso (EVANGELISTA et al., 2011; FARIA et al., 2011).

Finalmente, como o pinhão-manso é uma espécie que se encontra em processo de domesticação (LAVIOLA et al., 2014), espera-se com o melhoramento genético, a obtenção de variedades com maior potencial produtivo de óleo e sementes que apresente floração uniforme que permita uma única colheita durante o ano.

\section{CONCLUSÕES}

A irrigação favorece o aumento do teor de óleo em sementes de pinhão-manso.

Os frutos colhidos nos estádios misturados, maduros ou secos apresentam teor de óleo semelhante.

A irrigação e a colheita de frutos de pinhão-manso na coloração marrom (secos) proporcionam maior rendimento em massa seca de sementes.

\section{REFERÊNCIAS}

ANDRÉO-SOUZA, Y.; PEREIRA, A.L.; SILVA, F.F.S.; RIEBEIRO-REIS, R.C.; ARIZAMONTOBBIO, P.; LELE. S. Jatropha plantations for biodiesel in Tamil Nadu, India: Viability, livelihood trade-offs, and latent conflict. Ecological Economics, Amsterdam, v.70, n.2, p.189-195, 2010.

BRASIL. Ministério da Agricultura, Pecuária e Abastecimento. Regras para análise de sementes. Brasília, 2009. 399p.

CORVELLO, W.B.V.; VILLELA, F.A.; NEDEL, J.L.; PESKE, S.T. Maturação fisiológica de sementes de cedro (Cedrela fissilis Vell.). Revista Brasileira de Sementes, Londrina, v.21, n.2, p.23-27, 1999. 
DALLACORT, R.; MARTINS, J.A.; INOUE, M.H.; FREITAS, P.S.L.; KRAUSE, W. Aptidão agroclimática do pinhão-manso na região de Tangará da Serra, MT. Revista Ciência Agronômica, Fortaleza, v.41, n.3, p.373-379, 2010.

DRUMMOND, M.A.; SANTOS, C.A.F.; OLIVEIRA, V.R.; MARTINS, J.C.; ANJOS, J.B.; EVANGELISTA, M.R.V. Desempenho agronômico de genótipos de pinhão-manso no Semiárido pernambucano. Ciência Rural, Santa Maria, v.40, n.1, p.44-47, 2010.

DANTAS, A.A.A.; CARVALHO, L.G.; FERREIRA, E. Classificação e tendências climáticas em Lavras, MG. Ciência e Agrotecnologia, Lavras, v.31, n.6, p.1862-1866, 2007.

DRANSKI, J.A.L.; PINTO JÚNIOR, A.S.; STEINER, F.; ZOZ, T.; MALAVASI, U.C.;

MALAVASI, M.M.; Guimarães, V. F. Physiological maturity of seed sand colorimetry of fruits of Jatropha curcas L. Revista Brasileira de Sementes, Londrina, v.32, n.4, p.158-165, 2010.

EVANGELISTA, M.R.V.; CASTRO, R.D.; DANTAS, B.F. Efeito da salinidade na germinação de sementes e no crescimento inicial de mudas de pinhão-manso. Revista Brasileira de Sementes, Londrina, v.32, p.83-92, 2010.

EVANGELISTA, A.W.P.; MELO, P.C.; OLIVEIRA, E.L.; FARIA, M.A. Produtividade e rendimento de sementes de pinhão-manso submetido à irrigação e adubação com OMM-Tech. Engenharia Agrícola, Jaboticabal, v.31, n.2, p.315-323, 2011.

FARIA, M.A.; EVANGELISTA, A.W.P.; MELO, P.C.; ALVES JÚNIOR, J. Resposta da cultura de pinhão-manso à irrigação e à adubação com OMM-Tech®. Irriga, Botucatu, v.16, n.1, p.70-81, 2011.

GANGAL, S.; SHARMAA, S.; RAUFA, A. Putranjiva roxburghii seeds: Oil content and fatty acid composition during different stages of seed maturity. Journal of Pharmacy Research, Ooty, v.2, n.11, p.1666-1668, 2009.

JUHÁSZ, A.C.P.; BATISTA, D.L.M.; SOARES, B.O.; PIMENTA, S.; RABELLO, H.O.;

RESENDE, M.D.V. Parâmetros genéticos e ganho com a seleção para populações de pinhão-manso (Jatropha curcas). Pesquisa Florestal Brasileira, Colombo, v.30, n.61, p.25-35, 2010.

LAMARCA, E.; VIERA, J.P.; BORGES, I.F.; DELGADO, L.F.; TEIXEIRA, C.; CAMARGO, M.O.B.P.; FARIA, J.M.R.; BARBEDO, C. Maturation of Eugenia pyriformis seeds under different hydric and thermal conditions. Anais da Academia Brasileira de Ciências, Rio de Janeiro, v.85, n.1, p.223-233, 2013.

LAVIOLA, B.G.; SILVA, S.D.A.; JUHÁSZ, A.C.P.; ROCHA, R.B.; OLIVEIRA, R.J.P.; ALBRECHT, J.C.; ALVES, A.A. Desempenho agronômico e ganho genético pela seleção de pinhão-manso em três regiões do Brasil. Pesquisa Agropecuária Brasileira. Brasília, v.49, n.5, p.356-363, 2014.

MAEDA, J.A.; UNGARO, M.R.G.; LAGO, A.A.; RAZERA, L.F. Estádio de maturação e qualidade de sementes de girassol. Bragantia, Campinas, v.46, n.1, p.35-44, 1997.

MARCOS FILHO, J. Fisiologia de sementes de plantas cultivadas. Piracicaba: FEALQ, 2005, 495p.

MARTINS, L.D.; TOMAZ, M.A.; AMARAL, J.F.T.; LAVIOLA, B.G.; BORCARTE, M. Desenvolvimento inicial de mamona e pinhão-manso em solo submetido a diferentes corretivos e doses de fósforo. Revista Verde, Mossoró, v.5, n.1, p.143-150, 2010.

MELHORANÇA FILHO, A.L.; PEREIRA, M.R. R.; SILVA, J.I.C. Potencialidade energética em extratores e tempos de extração do óleo de pinhão-manso (Jatropha curcas L.) em soxletter.

Bioscience Journal, Uberlândia, v.26, n.2, p.226-230, 2010.

NERY, A.R.; RODRIGUES, L.N.; FERNANDES, P.D.; CHAVES, L.H.G.; FERREIRA, D.J.L. Produção do segundo ciclo do pinhão-manso irrigado com águas salinizadas em ambiente 
protegido. Revista Brasileira de Engenharia Agrícola e Ambiental, Campina Grande, v.17, n.5, p.531-536, 2013.

NUNES, E.N.; NASCIMENTO, D.A.M.; ALVES, A.G.; SUASSUNA, J.F.; NASCIMENTO, R. Crescimento de cultivares de mamona (Ricinus communis L.) em diferentes níveis de água no solo. Scientia Plena, Aracajú, v.9, n.10, p.1-10, 2013.

OLIVEIRA, J.S.; LEITE, M.P.; SOUZA, L.B.; MELLO, V.M.; SILVA, E.C.; RUBIM, J.C.; MENEGHETTI, S.M.P.; SUAREZ, P.A.Z. Characteristics and composition of Jatropha gossypiifolia and Jatropha curcas L. oils and application for biodiesel production. Biomass and Bioenergy, Silver Spring, v.33, n.3, p.449-453, 2009.

PARAWIRA, W. Biodiesel production from Jatropha curcas: A review. Scientific Research and Essays, Abraka, v.5, n.14, p.1796-1808, 2010.

PESSOA, A.M.S.; MANN, R.S.; SANTOS, A.G.; RIBEIRO, M.L.F. Influência da maturação de frutos na germinação, vigor e teor de óleo de sementes de pinhão-manso (Jatropha curcas L.). Scientia Plena, Aracajú, v.8, n.11, p.1-11, 2012.

PIÑA-RODRIGUES, F.C.M.; AGUIAR, I.B. Maturação e dispersão de sementes. In: AGUIAR, I.B.; PINÃ-RODRIGUES, F.C.M.; FIGLIOLIA, M.B. Sementes florestais tropicais. Brasília: ABRATES, 1993. p.215-274.

PONCIANO DE DEUS, F.; FARIA, M.A. ; OLIVEIRA, E.L. ; CASTRO NETO, P. Jatropha Seed Oil Content and Yield Under Different Irrigation and Potassium Fertilization Levels. Engenharia Agrícola, Jaboticabal, v.32, p.1089-1096, 2012.

SANTOS, S.B.; MARTINS, M.A.; AGUILAR, P.R.; CANESCHI, A.L.; CARNEIRO, A.C.O.; DIAS, L.A. Acúmulo de matéria seca e óleo nas sementes de pinhão-manso e qualidade do óleo extraído. Revista Brasileira de Engenharia Agrícola e Ambiental, Campina Grande, v.16, n.2, p.209-215, 2012.

SCHIAVO, J.A.; SILVA, C.A.; ROSSET, J.S.; SECRETTI, M.L.; SOUSA, R.A.C.; CAPPI, N. Composto orgânico e inoculação micorrízica na produção de mudas de pinhão-manso. Pesquisa Agropecuária Tropical, Goiânia, v.40, p.322-329, 2010.

SOUSA, A.E.C.; GHEYI, H.R.; SOARES, F.A.L.; MEDEIROS, E.P.; NASCIMENTO, E.C.S. Teor de óleo no pinhão-manso em função de lâminas de água residuária. Pesquisa Agropecuária Brasileira, Brasília, v.46, n.1, p.108-111, 2011. 